\title{
COMMENTARY
}

\section{Parra and the Journal of Scientific Exploration}

\author{
Stephen E. Braude
}

Submitted June 29, 2021; Accepted June 29, 2021; Published September 15, 2021

https://doi.org/10.31275/20212247

Creative Commons License CC-BY-NC

Michael Nahm's report in this issue of the JSE deftly presents many of the scholarly offenses perpetrated by Alejandro Parra. Some of those not mentioned had to do with Parra's submissions to the JSE, and I feel it's important to add those to the record.

JSE published a retraction notice earlier this year (Volume 35, Issue 1) and provided examples of Parra's plagiarism. Moreover, the Journal rejected another paper in which we found substantial plagiarism. But Parra's boldest effort was his submission, under his own name, of a paper by an Argentinian author, Anna Conforte-in fact, a paper Parra had published in his own newsletter. But Parra never indicated that the paper was written by someone else. Several people independently and carefully compared the English submission to the original Spanish. All agreed that Parra apparently simply auto-translated the paper to clumsy English and presented it as his own work.

During an extended email exchange with Parra, I challenged him to account for this. His response to that challenge, and other charges of plagiarism, was not only dishonest, but it betrayed a shocking failure to grasp the seriousness of his actions. On March 9, 2021, I wrote to him:

Let's focus first on your attempt to deny plagiarizing Anna Conforte's paper. You claim that the two of you worked on the English version together. Nevertheless, the fact remains that Anna is not listed as author anywhere in the paper, and (more seriously) there is no reference in the submitted paper to Anna's original article. Now it so happens that your name is also not on the MS submitted to the JSE. That's because the MS was submitted in the 
usual way for blind review, with only a title and with no authors listed-a common practice in scholarly journals. Still, there's indisputable evidence that you submitted the paper as if you were the sole author. In the JSE online submission system, you listed only yourself as author, even though you had the clear option [a button in bold letters] to list co-authors. We've located the attached screenshot of your submission page, showing clearly only your name listed as sole author, but also showing a link you could have used to add other names.

To make matters worse, in order to complete your submission in the JSE's online system, you were required to check several boxes shown in the 2nd screenshot. One of those boxes required you to certify that the submission had not been previously published. But then it's blatantly false for you to claim that you only realized later that the JSE doesn't publish previously published papers. You checked the box stating that the paper had not been previously published! There is no mystery about what you were doing. You clearly attempted to pass off Anna's paper as your own. And it's equally clear that you're lying more now about the matter.

Then on March 19, 2021, Parra wrote me:

Regarding the case of Anna Conforte, as I explained, her article unfortunately derived a chain of confusions, no perspicacy [sic]: The initial purpose was to translate into English and add other sources and illustrations of her original article in Spanish in order to publish it in "Journal of the Society for Psychical Research" (rejected) and then to "History of Human Science" (letter and first page attached) which was rejected by the editor (only one reviewer out of three had accepted it with changes). Finally, I hoped for a third chance in the "Journal of Scientific Exploration." Although Anna finally resigned due to lack of interest and I was "stuck" with an unfair accusation of TOTAL plagiarism because the article had been published in Spanish on my own website ... Here, due my mistake to updown [I believe Parra meant "upload"] the article in the online platform of the JSE (not any hidden reasons), I did not enter the name of the second author, but I have documented the exchange of emails of our agreement to translate the manuscript signed by both.

I replied to Parra on March 21: 
... your timeline for the Conforte submission seems to be inaccurate. You claim you submitted that paper to the JSE as a third choice, after its rejection by the JSPR and HHS. That seems clearly to be false. Your submission to the JSE is in fact dated March 28, 2020 (and on April 3 we sent you a letter requesting major revisions). But the letter of submission to HHS that you sent to us is dated May 1, 2020. So I'm sure you can understand why your version of the events looks to us like another piece of Parra fiction.

Moreover, our correspondence with you about the Conforte paper continued for several months, during which time you apparently sought publication in other journals, a practice widely recognized as improper by the scholarly community (by contrast, books may legitimately be peddled simultaneously to more than one publisher). We even have an email from you dated May 22, 2020, indicating that you were still working on your revisions. Needless to say, I shouldn't have to point out to you the impropriety of your actions. But again, your behavior over that paper and your continued protestations about it only reinforce general suspicions about your scholarly and personal integrity.

JSE Managing Editor Kathleen Erickson provided me with an even more revealing timeline. She noted the following:

3/28/2020 He submitted the Conforte paper without her name. $4 / 2$ JSE sent a decision letter asking him for major revisions.

5/22 The Managing Editor sent him an email (not from the OJS

submission system) but from the Journal email address

reminding him about working on a revision.

$5 / 22$ He responded "Firstly, I am working in the text."

Then nothing until we started investigating the content of the paper (in late 2020 and early 2021).

I should add to this that I contacted Anna Conforte on February 13, 2021 (almost a year after Parra had submitted her paper to the JSE), to alert her to the situation. And on March 8, she replied "I am the ONLY author of the article and it has already been published in Spanish. I hope it is not sent to be evaluated or published in any other Journal."

One of the most astonishing aspects of my exchanges with Parra during this time is his repeated effort to minimize the amount of plagiarism uncovered, as if to say "It's not that bad." For example, on 
March 31, 2021, Parra wrote

I counted only ten plagiarized/paraphrased sentences of 33 sentences in the Introduction section (approx. 30\%), which it is reduced taking 130 sentences of the total article (taking Introduction, Method and Discussion sections except Results) which reduce to $7.7 \%$ of plagiarism ... really very low.

Of course, no plagiarism is acceptable, and, interestingly, Parra's attempted excuse flies in the face of what he wrote on March 8:

It should not be necessary to say that plagiarism constitutes a serious contradiction of the most elementary rules of scientific conduct, an execrable crime that must be denounced and condemned by the scientific community. Indeed, given that I am an academically trained scientist, a member of the scientific community, I am certainly a person who should be familiar with the most basic rules of 'good scientific practice'.

Although I hope that we at the JSE never encounter another case of plagiarism, we have purchased plagiarism-detection software which we plan to employ liberally.

I should add that I'm pleased by the rapid and coordinated response of the parapsychological community to this affair. The only thing that slowed it down at all was the continued discovery of previously unidentified instances of plagiarism, going as far back as the 1990 . 